\title{
Design guidelines for a robust and reliable solar thermal heating and cooling system
}

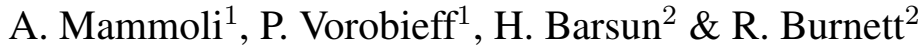 \\ ${ }^{1}$ Department of Mechanical Engineering, The University of New Mexico, \\ USA \\ ${ }^{2}$ Physical Plant Division, The University of New Mexico, USA
}

\begin{abstract}
The use of solar energy at the building scale today presents two viable options: grid-tied photovoltaic systems, and thermal systems utilizing absorption or adsorption cycles for cooling. The economic viability of either option is presently commensurate, however, specifically for the case of thermal systems, there is a major caveat, namely that the system must truly save energy, and must be reliable over its typical expected lifetime. While the basic design of a solar thermal system is relatively simple, there are many details that, if not carefully considered, can lead to poor performance, lack of reliability, and potentially catastrophic failure. Based on experience in designing, building, operating and analyzing such a system for several years, a set of guidelines is presented for each major system component, namely the solar loop, hot storage, cold storage, the heating and cooling subsystems, and the control system. These design recommendations should assist engineers in preventing costly mistakes that are difficult to correct. If followed, the guidelines should also reduce maintenance and prolong trouble-free performance of building-scale thermal systems.
\end{abstract}

Keywords: robust design, reliability, economic performance, energy efficiency.

\section{Background}

Building operation comprises a substantial fraction (40-50\%) of the overall energy budgets of industrially developed countries [1] and an even larger fraction of the electric energy budgets $(>70 \%)$. The advantages of minimizing the related energy expenditures are obvious, and have studied extensively in the last several decades, especially since the first and subsequent energy crises raised awareness 
of the necessity of energy conservation, and studies of the effect of anthropogenic greenhouse gas emission revealed its role in the global climate change. Along with energy efficiency, the latter motivates transition away from fossil energy sources and integration of renewable-energy generation and smart grid concepts into new buildings.

Energy-efficient building-scale thermal system design that uses renewable energy has been the subject of several recent books [2-4]. However, while it is possible to find a good general overview of the design practices, very often specific implementation details play a disproportionate role in determining the efficiency and ease of maintenance of a real-world building thermal system.

This paper provides specific recommendations for components that are quite common in buildings with solar thermal systems. These recommendation are based on several years of experience in design, maintenance, and optimization of a stateof-the-art solar-assisted HVAC setup that is described in the following section.

\section{System description}

The system installed at the University of New Mexico has been described in detail elsewhere [5-8]. Its layout (Fig. 1) is fairly typical. In the solar loop, glycol is circulated by pump P4 from the outlet of the heat exchanger HX, through an array of flat plate solar collectors, then through an array of vacuum tube solar collectors, to the inlet of the heat exchanger. Pump P5 draws water from the bottom of the hot water tank HWT, circulates it through the lower temperature side of the heat exchanger HX, and then to the top of the tank.

In the heating season, water from the top of the hot storage is drawn by pump P3 and circulated through a set of water-air heat exchangers, which heat air delivered to the building, and is subsequently returned to the bottom of the hot storage.

In the cooling season, water from the top of the hot storage tank is drawn by pump P3 and circulated through the absorption chiller's generator coil, then returned to the bottom of the hot storage. Return water from the cooling coils (another set of water-air heat exchangers which cool air delivered to the building) is directed by pump P2 to the evaporator section of the absorption chiller, where it is chilled and returned to the cooling circuit upstream of the coils. If the cold water production exceeds building demand, excess chilled water is stored in the cold water tanks (CWT).

The cold water tanks are charged at night to use off-peak power prices, and depleted during the day. During night-time charging, pump P1 draws water from the top of the cold storage, pumps it through a heat exchanger cooled by the campus chilled water system, and then to the bottom of the cold storage. During the daytime, chilled water is drawn by pump P1 from the bottom of the cold tanks, routed through the cooling coils, and returned to the top of the cold storage.

The combined solar and building heat is removed from the chiller by a cooling tower. Pump P6 draws water from the sump, pumps it through the chiller condensing coils, and then to the cooling tower. Water from the cooling tower flows back to the sump by gravity. 


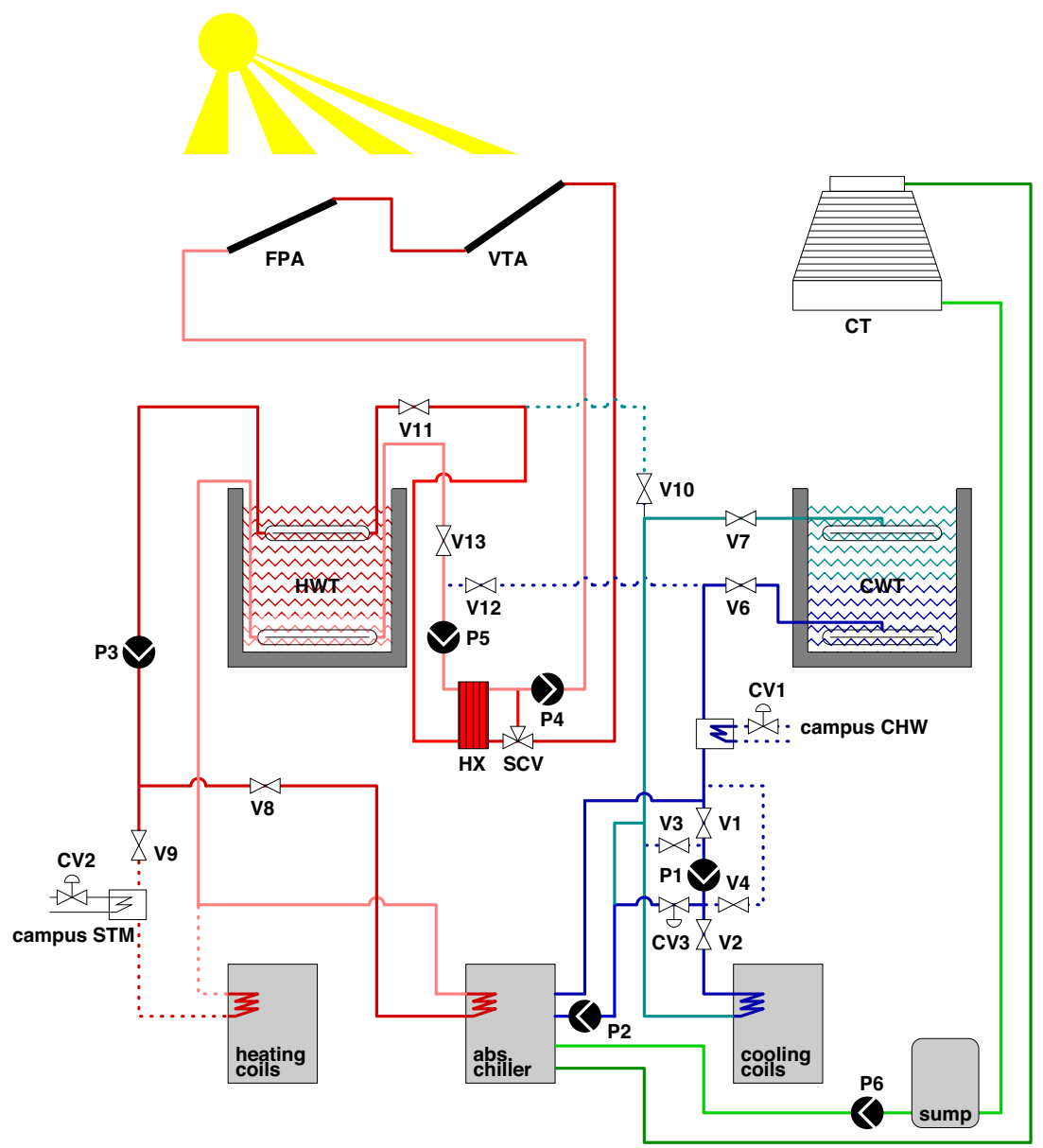

Figure 1: Schematic of the solar thermal system showing solar collectors (flat panel arrays FPA and vacuum tube arrays VTA), hot (HWT) and cold (CWT) storage tanks, absorption chiller, heating and cooling coils, and ancillary equipment layout.

\section{The solar loop}

Optimization of the solar loop involves balancing initial costs with running costs and reliability. First, it is necessary to choose the heat medium which will not freeze at temperatures regularly occurring in the cold season. A non-toxic $35 \%$ propylene glycol $/ 65 \%$ water mixture was selected to minimize problems due to toxicity at a small thermal performance detriment. Its freezing point, approximately $-17.8^{\circ} \mathrm{C}\left(0^{\circ} \mathrm{F}\right)$ is suitable for Albuquerque's climate, in which such temperatures occur only every several years. When the one of the two outside air 
temperature sensors detects temperatures below $-12^{\circ} \mathrm{C}$, active freeze protection is enabled. The solar loop pump P4 is activated, the three-way valve SCV allows glycol to flow through the heat exchanger HX, and pump P5 circulates water from cold storage (which is still warm enough to maintain the glycol temperature to well above freezing) through the water side of the heat exchanger.

The three-way valve SCV can isolate the solar loop from the heat exchanger. This is useful during winter nights, when thermosyphoning would otherwise allow sub-freezing glycol to enter the heat exchanger and thus freeze the water in its lower-temperature side. the loop can also be operated in isolated mode in the morning, while the solar loop is heating up. Finally, the valve can be used to regulate temperature in case of failure of the pump speed control. An expansion tank is located in a heated space, just downstream of the solar collector field. This location was chosen because it experiences the smallest pressure variations, which result as a consequence of heat medium flow rate through the system.

Piping selection is very important - pressure losses result in additional pumping power. As a rule of thumb, electric energy should be considered seven times more valuable than heat, using the typical COP of absorption and compression chillers of 0.7 and 5 respectively. Thus, for example, $1 \mathrm{~kW}$ of pumping loss offsets $7 \mathrm{~kW}$ of thermal heat collection rate. Thus, piping pressure losses should account for a small fraction of overall pumping requirements. The majority of the pumping losses are generally due to the solar collectors, which can be arranged in series or in parallel. For a given field temperature gain, the flow rate through each collector is proportional to the number of collectors connected in series. Pressure loss through an individual collector is generally proportional to the square of the flow rate. Thus, overall the pumping losses through the collector field are proportional to the third power of the number of collectors connected in series. Parallel arrangements are therefore preferable, from the point of view of pumping losses, to series arrangements. Therefore, while the initial cost of plumbing for series arrangements is generally less expensive, these savings (which can be substantial) must be balanced against pumping costs over the expected lifetime of the system, and by the cost of the larger pump(s) necessary to maintain the required flow rates.

Temperature control is achieved by adjusting the speed of the circulation pump ( $\mathrm{P} 4$, a 4-stage centrifugal pump with a three-phase, $7 \mathrm{~kW}$ AC motor) via a variable frequency drive (VFD). Since pumping costs are proportional to the square of the pump speed, substantial savings are obtained by reducing pump speed when possible, i.e. off solar peak. A single-stage, $7 \mathrm{~kW}$ AC pump, or a $1 \mathrm{~kW}$ batterypowered DC pump provide circulation in the case of failure of the primary pump or loss of AC power respectively. Temperature control in this case is obtained via the three-way valve SCV.

A final design suggestion relates to he ability of the collector system to withstand wind loading. In many cases, the manufacturer-provided rack/mounting systems require additional bracing. Even small oscillations of collector rows, especially if connected in series, can eventually lead to leaks in the collectorcollector coupling, which, if left unchecked, ultimately may lead to more serious consequences (pump cavitation, vapor lock, emulsification of the glycol/water 
mixture. Ultimately, with tens or even hundreds of connections for a typical system, a completely leak-proof system is beyond realistic expectation., and an automatic glycol make-up system should be considered for a robust installation.

\section{The hot storage system}

How water storage is essential for solar heating and cooling systems, both for smoothing intermittency and for decoupling the load from the production. A welldesigned storage system provides a steady supply of hot water, at constant temperature, to the absorption chiller or to the heating coils. Hot storage can be pressurized or atmospheric. Closed loop, pressurized systems allow higher working temperatures (necessary, for example, in the case of double-effect chillers), and are less susceptible to evaporative heat loss. In a closed system, water treatment requirements are less severe. On the other hand, pressurized systems are more expensive than atmospheric systems, and are subject to more stringent design requirements.

Atmospheric pressure storage systems are restricted to temperatures below the boiling temperature of water at the location of the installation (for example, $93^{\circ} \mathrm{C}$ for Albuquerque). However, the cost is lower, especially as the tank size increases. Running a typical building-scale chiller (in the present case, a Yazaki SH-20, $75 \mathrm{~kW}_{t}$ ) for one hour while a bank of clouds passes by requires a hot water reserve of approximately $3000 \mathrm{~kg}$. Load shifting requires even more storage. Typically the maximum cooling load occurs approximately three hours after the solar peak, so that shifting the additional cooling capacity accordingly would require a tank with $9000 \mathrm{~kg}$ capacity. If cold storage is also a part of the system, it also can be used for load shifting. However, a large storage tank may allow operation of the chiller at times of day when ambient temperature is lower, so that the cooling tower operates more efficiently, with reduced use of the cooling fan.

To minimize heat losses, the bottom and sides of the tank must be highly insulated with materials suitable for the highest water temperature in the system. In the present case, two layers of insulation were used for the sides and bottom. The inner layer, adjacent to the water, is polyurethane foam, which can withstand continuous exposure to $120^{\circ} \mathrm{C}$, with a thickness of $0.1 \mathrm{~m}$. The outer layer, which is exposed to much lower temperature, consists of $0.2 \mathrm{~m}$ thick polystyrene panels. The tank is lined with a high-density polyethylene liner.

The top of the tank should also be thoroughly insulated. This component is actually more critical that the other surfaces because evaporative losses can become large. Ideally, a floating 'lid' could minimize evaporation, and also accommodate thermal expansion and contraction of the water mass. Such a system was implemented initially in the present system. While its initial performance was excellent, it rapidly degraded, due to the de-polymerization and related embrittlement of the polycarbonate floating mats. A second design consisted of a double layer metal 'suspended ceiling', with a $0.05 \mathrm{~m}$ air gap between the metal sheets. Polystyrene insulation panels of $0.05 \mathrm{~m}$ thickness were laid above the metal ceiling. 
Water from the bottom of the hot tank is pumped through the solar heat exchanger HX by pump P5. A battery powered $48 \mathrm{~V}$ DC backup pump provides enough flow to dissipate the heat from the solar system for several hours, as a failsafe for the main AC pump failure, a loss of grid power, or of backup generator power.

Water is delivered or drawn from hot storage via two flow-through diffusers, one at the bottom of the tank, the other near the top. In a flow-through diffuser [7], water is supplied at one end and drawn from the other. The flow rate difference between the supply and draw is balanced by the storage tank. This design allows using two rather than four diffusers, and if the supply and load are well-matched, the storage loss that would be incurred by sending water to storage before drawing it again is substantially reduced. The diffusers are constructed using CPVC, which is able to withstand the working temperatures of the water and does not corrode.

It is recommended that all piping leading to and from hot storage be as short as possible, routed below the water line at all points, and that the pumps be located as close as possible to the storage tank. This is particularly important in the case of the pump serving the chiller (P3), which draws water at a temperature close to boiling. If the piping between the storage tank and the pump is too long, and particularly at high pipe elevations, the water might flash to steam, severely disrupting the pump's capacity to sustain the required flow rate. For the same reason, all hot water pumps should be located as low as possible with respect to the hot storage. Finally, if all piping is below the water line, any leaks in the piping will result in outward leaking of water, rather than inward air leaks, which could lead to loss of priming.

\section{The cold storage system}

Cold storage is particularly important for climates where cooling dominates the thermal load, which certainly is the case for New Mexico. At the same time, the useful temperature difference (assuming liquid water is the energy storage medium) is about five times lower than it is for heating. This consideration is important when the size of the cold storage tanks is determined. The system discussed here uses seven tanks for cold storage and only one tank for hot storage.

Cold-water tanks located below ground level have reinforced concrete walls $0.3 \mathrm{~m}$ thick. Because temperature differences between the surroundings and the storage medium are much lower for cold storage, the concrete provides adequate insulation, eliminating the necessity for additional insulating materials. Evaporative losses are not a problem for cold storage either, so the tanks can operate quite well without a floating lid or an insulated suspended ceiling. What proved quite beneficial, however, was the installation of flexible polyurethane drop-in liners in the storage tanks. Without liners, cracks developing in the concrete lead to leaks.

Stable thermal stratification is maintained both in the hot and cold tanks, which makes it possible to use the same tank for drawing fresh storage medium (in the case of cold tanks, coldest water from the bottom) and for releasing the depleted medium (for cold tanks, warmer water that has passed through the air-handler 
coils is deposited near the top of the tank). Maintaining the stratification in the tanks requires properly designed and located diffusers to prevent forced convection and turbulence. The diffusers have the same orientation, with the warmer diffuser located at the top of one side of the tank, and the colder one - at the bottom of the opposite side of the tank. This arrangement avoids mixing by producing low velocity $(<2 \mathrm{~cm} / \mathrm{s})$, uniform temperature fluid flow in and out of the tank.

Earlier studies using the same storage tanks investigated the feasibility of changing the tank aspect ratio with baffles [9,10]. With diffusers installed as described above, stratification is sustainable without any baffling (in $4 \times 4 \times$ $4 \mathrm{~m}$ tanks). Moreover, baffles significantly complicate tank maintenance, liner installation, etc.

What was also found to be quite necessary was chemical water treatment for the cold storage - without it, the tanks too easily provide breeding ground for many kinds of lifeforms, which in turn increases maintenance expenses and corrosion.

Finally, there is a cost-efficient failsafe for solar thermal systems with storage that are located in climates with occasional extreme winter temperatures. Water in cold storage can be used to heat the thermal medium in the solar loop to prevent it from freezing. In December 2010, when outside temperatures fell as low as $-16^{\circ} \mathrm{C}$ during the nights, cold storage water was run through the solar-loop heat exchanger while also running the solar loop pump, thus achieving freeze protection.

\section{The heating and cooling systems}

The building is heated and cooled by forced air, delivered via a dual-duct system. A large atrium in the building is served by an air handler which uses an air-water heat exchanger for heating and evaporative media for cooling. The remainder of the building is heated and cooled via water-air heat exchangers for both heating and cooling, located in several air handling units (AHUs).

During the heating season, water is drawn by pump P3 from the top flowthrough diffuser in the HWT and routed to several AHUs where water-air heat exchangers control the air temperature in the hot deck. Control valves in each air handler adjust the hot water flow to maintain a set hot deck temperature. The water temperature set point in the HWT is $60^{\circ} \mathrm{C}$, and is achieved whenever sufficient solar power is available. The temperature of the hot water supply to the AHUs is boosted by a steam-water heat exchanger (campus STM in Fig. 1) if the temperature falls below $55^{\circ} \mathrm{C}$. Pump P3 is a tandem set-up, in which one of the two identical pumps serves as the primary pump, while the other is on stand-by.

During the cooling season, the building is cooled by depleting cold storage (approximately 60-65\% of the total load) with the balance supplied by the absorption chiller. In charging mode, pump P1 (a set of tandem pumps) draws water from the top of the CWT, at approximately $18^{\circ} \mathrm{C}$, routes it through a plate-and-frame heat exchanger, and returns it to the bottom of the CWT at approximately $8^{\circ} \mathrm{C}$. Flow rates are controlled so that water on the cold side of the heat exchanger (from the central campus chilled water system) enters at $6.5^{\circ} \mathrm{C}$ and exits at $14.5^{\circ} \mathrm{C}$. 
When a sufficient amount of hot water at $84^{\circ} \mathrm{C}$ accumulates in the HWT, the absorption chiller startup procedure begins. Chilled water from the AHU return is pumped through the chiller evaporator by pump P2 (also a tandem setup). The cooling water pump P6 is activated. Meanwhile, the heating water supply is also activated. To avoid a daily thermal shock, the heating water flow rate is ramped up slowly, beginning from a level of $60 \%$ pump speed, at a rate of $3 \%$ per minute, until the desired chiller outlet temperature is reached. The absorption chiller is enabled by the digital control system. If internal checks are satisfied, the solution pump is enabled and absorption cooling begins. Steady-state is reached in approximately 10 minutes from procedure initiation. The accumulated water in the HWT prior to chiller startup ensures that more than one daily startup occurs seldom. More than two startups have not been observed to date.

A very important and often-overlooked design aspect of systems with absorption chillers is their high cooling demand. For a typical electric chiller, for every unit of cooling, an additional $0.20-0.25$ units of mechanical work eventually add to the overall load on the cooling tower, for absorption chillers every unit of cooling power is accompanied by an additional 1.4-1.5 units of heat input to the generator. Thus, the cooling tower for an absorption chiller must have approximately twice the capacity of the tower required for a compression system with the same rating. Moreover, the cooling water flow rate requirements also double, and the cooling water pump and related piping likewise must be upgraded. Inadequate cooling capacity is a common problem encountered during the commissioning of absorption-based systems.

\section{The control system}

For a system of this complexity, direct digital control (DDC) is a must. Reliability and autonomy are necessary features, given that, once commissioned, a typical system is expected to function without supervision. Thus an industrial-grade HVAC controller is warranted. In the present case, the controller (Delta) is programmed in GCL+, a BASIC-like programming language. The control program is strongly structured into relatively simple and easily testable sub-programs, reducing the possibility of unpredicted logic flaws.

An effort was made to predict possible serious failures. For example, if the flow rate in the solar loop (measured by a flow meter) is below a certain threshold, while the pump is active, there are two possible causes - flow meter failure or loss of fluid. In the former case, it would preferable to keep the pump running to avoid collector overheating. However, if indeed there was a loss of fluid, running the pump dry would cause severe damage to the pump in a shorter time. Thus, the controller action under the 'no flow - pump on' scenario is to shut down the pump and alert one or more technical personnel who are able to take corrective action. Alerts are sent by the control system via email and text messaging.

In the case that $\mathrm{AC}$ power is lost (a low-probability event, which requires loss of grid power and failure of the emergency diesel generator), the entire system shuts down, except for the solar loop. Backup DC pumps on either side of the heat 
exchanger HX are able to run on battery backup for up to five hours. Automatic switches on the pumps fail closed, so that the backup pumps are enabled. Valves V10 and V12 fail open, while valves V11 and V13 fail closed. This way, the large chilled water storage tanks serve as a buffer to prevent either overheating (daytime) or freezing (night-time in winter) of the solar loop.

\section{Energy and economic performance}

Results of comparing the numerically predicted [7] and experimentally measured [8] performance of the system were quite interesting. In some cases (e.g., the operation of the solar loop), the agreement was excellent. The comparison also revealed weak points in the design, most of which have now been addressed. One such weak spot was the hot energy storage, with higher than expected evaporative losses from the top. Another problem lay with the air handlers that caused dramatic efficiency losses by allowing more outside air than necessary to enter the building - mostly due to baffles that failed to close completely. Improper operation of the air handling subsystem alone can negate all the benefits from active energy collection.

An economic study [8] revealed that in New Mexico, where the energy prices from utility companies are presently very low, installation of building-scale solar thermal systems offers very limited benefits, and these are only realized if the lifetime of the system is very long. At the same time, in environments with much higher energy costs (US Pacific coast, EU) installation of solar thermal building systems becomes economically viable with a much shorter term for return on investment. If the reduction in $\mathrm{CO}_{2}$ emissions due to system installation is explicitly taken into consideration (e.g., via monetized carbon credits), this further improves the economic viability of building-scale solar thermal systems. In any case, however, before considering installation of active energy capture systems in new designs or for building renovation, it is imperative to maximize the building energy efficiency by ensuring that all HVAC components operate properly, all control sequences are well thought-out, and all efficiency measures have been implemented, including minimization of evaporative and convection losses from hot storage, installation of proper pumping and plumbing, minimization of electric losses (with variable-frequency drives for all the pumps and fans), and elimination of air leaks in air handling units.

\section{Conclusions}

Design and implementation recommendations for building-scale solar thermal systems presented here emphasize efficient and trouble-free performance. Many suggestions include measures that would be equally applicable to an energyefficient building either with or without an active energy collection system (e.g., ensuring proper operation of air handling units). In the presence of a solar thermal system, specific optimization measures are also required (proper insulation for hot storage, diffusers that maintain stratification in the tanks, etc.). 
As the benefits of solar thermal systems are still realized over the long term (even in markets with high energy costs), the designer must overcome the temptation to cut initial costs and maximize performance at the expense of system reliability. Failsafes and some redundancy are essential for the long-term potential of the solar thermal system to be realized fully without costly repairs. Research is underway to support the integration of high-penetration, high intermittency distributed energy resources (e.g., rooftop PV) within a distribution feeder, by using thermal storage, as well as easily dispatchable energy resources such as fans.

\section{References}

[1] Mazria, E., It's the architecture, stupid! Solar Today, pp. 48-51, 2003.

[2] Henning, H.M., Solar-Assisted Air-Conditioning in Buildings. SpringerVerlag/Wien, 2004.

[3] Gevorkian, P., Sustainable Energy System Engineering: The Complete Green Building Design Resource. McGraw-Hill Professional, 2006.

[4] Vallero, D.A. \& Brasier, C., Sustainable Design: The Science of Sustainability and Green Engineering. Wiley, 2008.

[5] Ortiz, M., A TRNSYS model of a solar thermal system with thermal storage and absorption cooling. Master's thesis, The University of New Mexico, Albuquerque, NM, USA, 2008.

[6] Mammoli, A.A., Vorobieff, P. \& Menicucci, D., Promoting solar thermal design: the Mechanical Engineering building at the University of New Mexico. Management of Natural Resources, Sustainable Development and Ecological Hazards, Wessex Institute of Technology: Albuquerque, NM, USA, WIT Transactions on Ecology and the Environment, 2006.

[7] Ortiz, M., Barsun, H., He, H., Vorobieff, P. \& Mammoli, A., Modeling of a solar-assisted HVAC system with thermal storage. Energy and Buildings, 42, pp. 500-509, 2010.

[8] Mammoli, A., Vorobieff, P., Barsun, H., Burnett, R. \& Fisher, D., Energetic, economic and environmental performance of a solar-thermal-assisted hvac system. Energy and Buildings, 42, pp. 1524-1535, 2010.

[9] Wildin, M.W., A report on the mechanical engineering building at the University of New Mexico. Technical report, The University of New Mexico, Albuquerque, NM, USA, 1982.

[10] Wildin, M.W., Results from use of thermally stratified water tanks to heat and cool the Mechanical Engineering building at the University of New Mexico. Technical Report ORNL/Sub-80-7967/1, The University of New Mexico, Albuquerque, NM, USA, 1983. 